\title{
Estimation of Solar Radiation on Horizontal and Tilted Surface over Bangladesh
}

\author{
Mohammad Ashraful Islam1*, Md. Saiful Alam1, Komol Kanta Sharker², \\ Sanjoy Kumar Nandi ${ }^{1}$ \\ ${ }^{1}$ Department of Physics, University of Chittagong, Chittagong, Bangladesh \\ ${ }^{2}$ Department of Applied Chemistry and Chemical Engineering, Noakhali Science \& Technology University, \\ Sonapur, Bangladesh \\ Email: *asharifphys@gmail.com, saif10350@gmail.com, sharkerkomol@gmail.com,skumarnandi@yahoo.com
}

Received 10 December 2015; accepted 17 April 2016; published 20 April 2016

Copyright (C) 2016 by authors and Scientific Research Publishing Inc.

This work is licensed under the Creative Commons Attribution International License (CC BY).

http://creativecommons.org/licenses/by/4.0/

(c) (i) Open Access

\section{Abstract}

To estimate the monthly averaged solar radiations (global, diffuse and direct solar radiation) on horizontal surface and tilted surface over 10 stations (districts) in Bangladesh, thirty years monthly averaged data of various meteorological parameters namely the monthly averaged value of maximum temperature, minimum temperature, humidity and sunshine hours were used in this study. Assessment of the solar resources for the solar based renewable energy technologies of Bangladesh may be based upon this kind of measured data analyzed study. This study tried to estimate the monthly averaged solar radiation by presenting data in table and graph and finally analyze through equations and descriptions. Correlation between the measurements of monthly averaged solar radiation and the meteorological parameters was given for the selected 10 stations in Bangladesh. In conclusion, we tried to make a comparison among solar radiation on horizontal surface, fixed $20.83^{\circ}$ (degree) optimal tilt angle and variable optimal tilt surface at Dhaka station.

\section{Keywords}

Solar Radiation, Meteorological Parameters, Inclination Angle, Conversion Factor, Optimal Tilt Angle

\section{Introduction}

The social and economic development of a nation is assessed on the basis of energy consumption per capita. In advanced countries $7.35 \mathrm{KW}$ per person is required to maintain the standard of living and comfort. For Europe it

\footnotetext{
${ }^{*}$ Corresponding author.
}

How to cite this paper: Islam, M.A., Alam, Md.S., Sharker, K.K. and Nandi, S.K. (2016) Estimation of Solar Radiation on Horizontal and Tilted Surface over Bangladesh. Computational Water, Energy, and Environmental Engineering, 5, 54-69. 
is $5.02 \mathrm{KW}$ per person, $1.30 \mathrm{KW}$ per person in the developing countries and only $0.228 \mathrm{KW}$ per person in Bangladesh. Energy consumption per capita over the world is $2.37 \mathrm{KW}$ [1]. So, the countries poor in energy are in an extremely unhappy position. The world population will reach approximately 12 billion by the year 2100 . If the current trend in technological progress and innovation continues, the demand for energy then will be five times greater than what it is now. Thus it is obvious that the present exhaustible forms of conventional energy resources, such as wood, cool, natural gas and oil will not be able to meet this every increasing energy demand. Besides the fast rate of consumption of conventional energy resources, the other very important factor responsible for energy crisis is the odd distribution and consumption of these resources. This is to be mentioned here that one-third of the world population consumes about four fifths of the total world energy while a very meager share is left to the majority of the population living in developing or underdeveloped countries.

The present day energy crisis has therefore resulted in the search for alternate energy resources in order to cope with the drastically changing energy picture of the world. With the rapid industrialization and fast growth rate of energy consumption, the world will soon run out of its conventional fuel. This problem demands an urgent and serious attention, especially by the inhabitants of developing and underdeveloped countries, not only to the husbanding of present resources, but also to the short and long-term development of future energy resources. This is important because the social and economic development of these countries heavily leans on the consumption and harnessing of their energy resources. Out of the available alternate energy resources, solar energy has emerged as one of the most powerful, clean, safe and virtually inexhaustible sources of energy; world can depend on, in the years to come.

Solar energy is quite simply the energy produced directly by the sun and collected elsewhere, typically on the earth. The geographical location of Bangladesh lies between $20^{\circ} 34^{\prime}$ and $26^{\circ} 38^{\prime}$ North latitude and $88^{\circ} 01^{\prime}$ to $92^{\circ} 41^{\prime}$ East longitude, and is endowed with abundant sunshine for at least eight months of the year [2]. It has a total land area of 147,570 square $\mathrm{km}$. On an average $5 \mathrm{KW} / \mathrm{m}^{2}$ per day solar energy falling on this land over the year, in certain regions the bright sunny days may be more. Even if one percent of this land is used to harness solar energy for electricity generation at an overall efficiency of $12 \%, 7200 \mathrm{MWh} /$ year electricity is generated [3]. This is a redundant amount of electricity.

The availability of solar energy in a particular location depends basically on the astronomical, geographic and climatic factors, with greatest influences on atmospheric transmissivity given water vapor concentrations, aerosols and clouds [4] [5]. Bangladesh lies between $15^{\circ} \mathrm{N}$ and $35^{\circ} \mathrm{N}$ known as the most favorable belt embracing the regions endowed with the most suitable conditions for solar energy applications. In this respect, Bangladesh is fairly rich as far as solar radiation is concerned.

\section{Theoretical Analysis of Solar Radiation}

In this study, the value of solar radiation has been estimated on the basis of meteorological parameters of the last 30 years collected by Bangladesh Meteorological Department with the help of different empirical formulae. Solar radiations (global, diffuse and direct solar radiation) over 10 stations (districts) of Bangladesh has been predicted by using the value of monthly averaged of different parameters e.g. the monthly averaged value of maximum temperature, minimum temperature, humidity and sunshine hours for the period of 1980-2009 years. The analysis has been done by using MS Excel, Origin, SPSS.

\subsection{Estimation of Monthly Averaged Daily Radiation (Global, Diffuse and Beam) on Horizontal Surface}

Generally to estimate the monthly averaged daily global $(G)$ and diffuse $(D)$ radiation on a horizontal surface, following Garg and Garg, M. Hussain [6] correlation has been used.

$$
\begin{aligned}
& G=G_{o}\left(0.394+0.364 \frac{n}{N}-0.0035 w\right) \\
& D=G_{o}\left(0.306-0.165 \frac{n}{N}+0.0025 w\right)
\end{aligned}
$$

where, $G_{o}$ is the extra-terrestrial radiation, $N$ is the maximum duration for which the Campbell-Stakos sunshine recorder is active, $n$ is the sunshine duration and $w$ is the atmospheric water content. 
The total solar radiation on a horizontal surface is equal to the sum of diffuse and beam radiation on a horizontal surface. Therefore we can find out beam radiation $(I)$ by subtraction method

$$
I=G-D \text {. }
$$

Diffuse solar radiation represents the shortwave energy of solar origin scattered downwards by gas molecules, aerosols, water vapor and clouds in the atmosphere. The variability in the amount and type of cloud has a dominant role on the value of diffuse radiation. The solar scientist gave a theoretical relation between diffuse solar radiation $(D)$ and the clearness index $\left(K_{T}\right)$ which is given by

$$
\frac{D}{G}=c+d\left(\frac{n}{N}\right)
$$

where, $c$ and $d$ are the correlation coefficients. The values of $c$ and $d$ are obtained from monthly averaged data of all months of the year for a location. The term clearness index $K_{T}$ is defined as the ratio of monthly averaged radiation on a horizontal surface to the monthly averaged daily extraterrestrial radiation i.e.

$$
\frac{G}{G_{o}} \text {. }
$$

An angstrom like correlation using sunshine hour data

$$
\frac{D}{G}=c^{\prime}+d^{\prime}\left(\frac{n}{N}\right)
$$

has been used to compute diffuse radiation in terms of global radiation for different locations of Bangladesh. Here $c^{\prime}$ and $d^{\prime}$ are the constant and regression coefficient.

In case of direct solar radiation, a page likes regression using sunshine hour data

$$
\frac{I}{G}=e+f\left(\frac{G}{G_{o}}\right)
$$

and another angstrom like regression using sunshine hour data

$$
\frac{I}{G_{o}}=e^{\prime}+f^{\prime}\left(\frac{n}{N}\right)
$$

have been used to estimate monthly average direct solar radiation over Bangladesh. Here $e, f, e^{\prime}, f^{\prime}$ are the regression coefficients to be determined.

\subsection{Estimation of Monthly Averaged Daily Solar Radiation (Global, Diffuse and Beam) on Tilted Surface}

The method developed by Liu and Jordan [7] of estimating the average daily radiation for each month on a tilted south-facing surface is described in Klien's review paper [8]. It is also extended to calculate the radiation for off-south orientation (east or west of south). The average daily radiation on a tilted surface is given as

$$
G_{T}=R G=R K_{T} G_{o}
$$

where, $R$ is the ratio of the daily average radiation on a tilted surface to that on a horizontal surface for each month. $R$ can be estimated by considering individually the direct, diffuse and reflected components of radiation incident on the tilted surface. Assuming diffuse and reflected radiation to be isotropic, Liu and Jordan [9] suggest $R$ as equal to

$$
R=\left(1-\frac{D}{G}\right) R_{b}+\frac{D}{G}\left(\frac{1+\text { coss }}{2}\right)+\frac{\rho(1-\text { coss })}{2}
$$

where, $D$ is the monthly averaged daily diffused radiation, $R_{b}$ is the ratio of the average beam radiation on tilted surface to that on the horizontal surface, $s$ is the tilt angle from the horizontal and $\rho$ is the ground reflectance, usually taken to be 0.2 when there is no snow.

From a surface facing directly southwards 


$$
R_{b}=\frac{\cos (\varphi-s) \cos \delta \sin \omega_{s}^{\prime}+\left(\frac{\pi}{180}\right) \omega_{s}^{\prime} \sin (\varphi-s) \sin \delta}{\cos \varphi \cos \delta \sin \omega_{s}+\left(\frac{\pi}{180}\right) \omega_{s} \sin \varphi \sin \delta}
$$

where $\omega_{s}^{\prime}$ is the sunset hour angle for tilted surface given by

$$
\omega_{s}^{\prime}=\min \left\{\omega_{s} \cos ^{-1}(-\tan (\varphi-s) \tan \delta)\right\}
$$

where $\omega_{s}$ is the sunrise hour angle in radian and is given by

$$
\omega_{s}=\cos ^{-1}(-\tan \varphi \tan \delta)
$$

where, $\delta$ is the sun's declination which is the angular distance of the sun's rays north or south of the equator. Also

where $n$ is the day of the year.

$$
\delta=23.45 \sin \left[360 \times \frac{284+n}{365}\right]
$$

\section{Results and Discussion}

\subsection{Estimation of Solar Radiation on Horizontal Surface}

Calculation of global, diffuse and beam radiation for each station has been evaluated by using S. P. Garg and H. N. Garg formula [6], M. Hussain formula [6] and subtraction method. Monthly averaged daily global, diffuse and beam radiation in different stations of Bangladesh are shown in Figures 1-3.

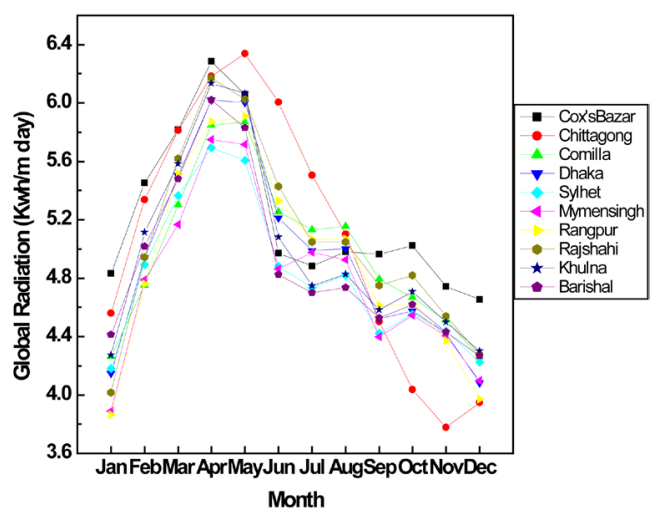

Figure 1. Illustrating the variation of monthly averaged global $(G)$ solar radiation over selected stations.

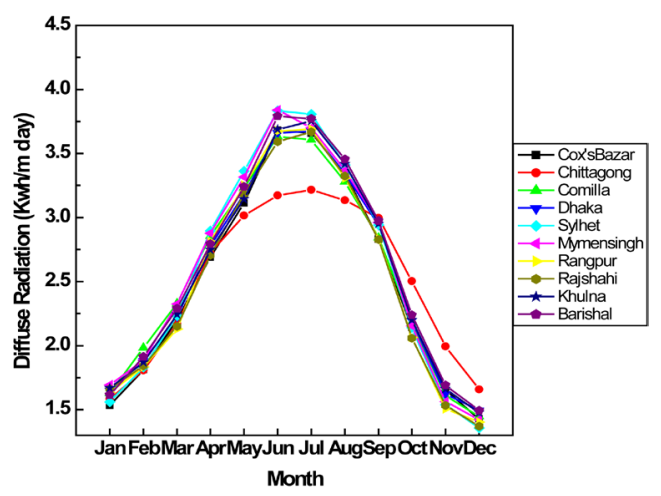

Figure 2. Illustrating the variation of monthly averaged diffuse $(D)$ solar radiation over selected stations. 


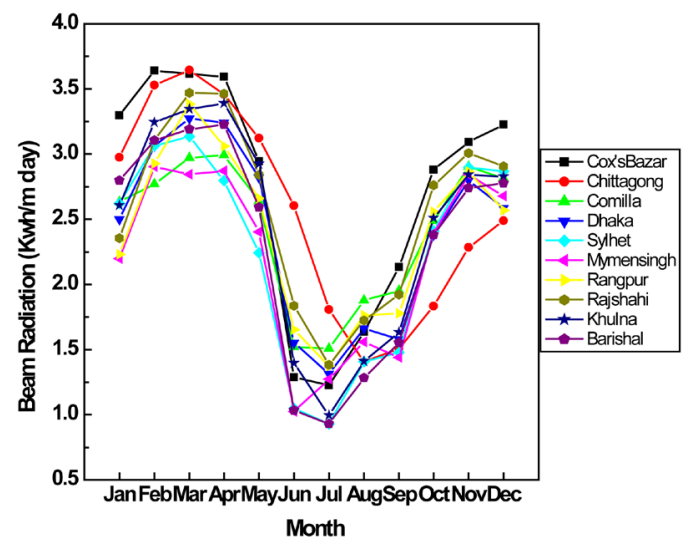

Figure 3. Illustrating the variation of monthly averaged beam $(I)$ solar radiation over selected stations.

The dependence of global solar radiation on maximum temperature is intensified by sunshine hour. From all the curves, it is clear that the first peak in the global solar radiation occurs during summer (April/May). In first period; both sunshine hour and temperature are high. But the second peak occurs in August (autumn) which is not so prominent, due to high temperature but short sun shining period. Again, during winter (November/ December), though there is enough sun shining periods but the temperature is low. Therefore, it results in low global solar radiation. The maximum value of global radiation is $6.34 \mathrm{Kwh} / \mathrm{m}^{2}$ day in Chittagong for the month of April when the bright sunshine hour, average temperature and humidity are (8.1 hours), $\left(28^{\circ} \mathrm{C}\right)$ and $(77 \%)$ respectively, contrary to the minimum value of global radiation is $3.74 \mathrm{Kwh} / \mathrm{m}^{2}$ day in Chittagong for the month of November when the bright sunshine hour, average temperature and humidity are (5.2 hours), $\left(25^{\circ} \mathrm{C}\right)$ and (76\%) respectively. The average maximum value of global radiation has been found in Cox's Bazar $5.22 \mathrm{Kwh} /$ $\mathrm{m}^{2}$ day and the minimum value is $4.75 \mathrm{Kwh} / \mathrm{m}^{2}$ day in Mymensingh.

The diffuse solar radiation depends on relative humidity and atmospheric water content. It increases with the decrease of sun shining hour and increase of atmospheric water content. Therefore, the diffuse radiation is maximum in June/July (rainy) and minimum in December/January (winter). The maximum value of diffuse radiation is $3.83 \mathrm{Kwh} / \mathrm{m}^{2}$ day in Sylhet for the month of June when the bright sunshine hour, average temperature and humidity are $\left(3.77\right.$ hours), $\left(28.07^{\circ} \mathrm{C}\right)$ and $(86.1 \%)$ respectively, and the minimum value is $1.37 \mathrm{Kwh} / \mathrm{m}^{2}$ day in Rajshahi for the month of December when the bright sunshine hour, average temperature and humidity are (8.05 hours), $\left(19.01^{\circ} \mathrm{C}\right)$ and $(77.6 \%)$ respectively.

The direct solar radiation is directly related to sunshine duration. The direct solar radiation is, therefore, maximum in March/April (summer) and minimum in July (rainy). The peak value of direct radiation is 3.64 $\mathrm{Kwh} / \mathrm{m}^{2}$ day in Chittagong for the month of March when the bright sunshine hour, average temperature and humidity are $\left(8.53\right.$ hours), $\left(25.60^{\circ} \mathrm{C}\right)$ and $(73.28 \%)$ respectively, and the minimum value is $0.92 \mathrm{Kwh} / \mathrm{m}^{2}$ day in Sylhet for the month of July when the bright sunshine hour, average temperature and humidity are (3.64 hours), $\left(28.40^{\circ} \mathrm{C}\right)$ and $(86.9 \%)$ respectively.

\subsection{Monthly Variation of Clearness Index}

From Figure 4 of clearness index at different stations, we can predict four solar seasons for Bangladesh. These seasons are as follows:

Season-1: December, January, February; Season-2: March, April, May; Season-3: June, July, August; Season-4: September, October, November.

\subsection{Determination of Regression Coefficient and Constant of Different Stations}

Table 1 shows the values of the regression coefficients and constants $a, b, c, d, c^{\prime}, d^{\prime}, e, f, e^{\prime}, f^{\prime}$ for ten stations of Bangladesh. It is evident that, the values of the coefficient " $a$ " vary from 0.232 to 0.257 , while the coefficient " $b$ " varies from 0.487 to 0.573 . Using the average values of the coefficients a and constant $b$ for ten stations, a approximate equation recommended for the estimation of monthly averaged global solar radiation for any area 


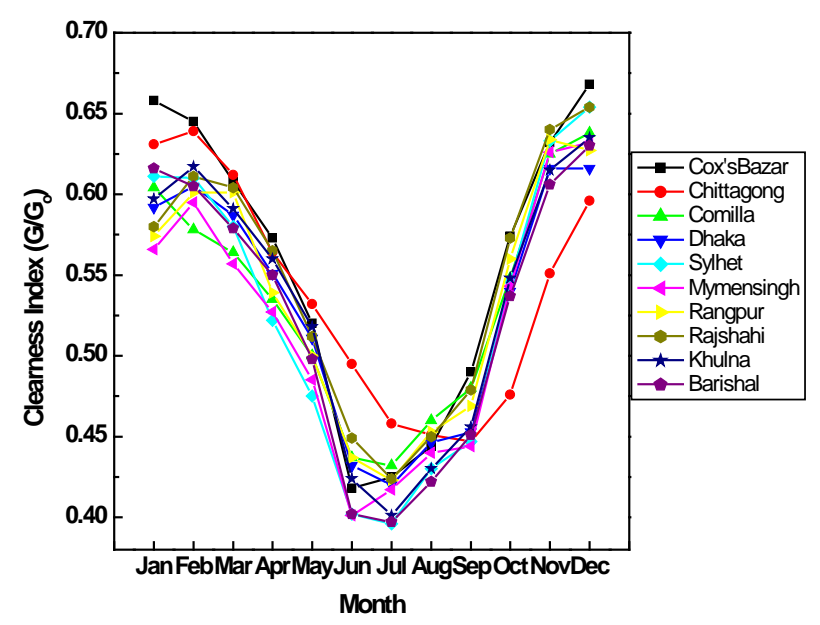

Figure 4. Monthly variation of clearness index.

Table 1. The values of regression coefficient and constants for different stations are shown in following table.

\begin{tabular}{ccccccccccc}
\hline Station & $a$ & $b$ & $c$ & $D$ & $c^{\prime}$ & $d^{\prime}$ & $E$ & $f$ & $e^{\prime}$ & $f^{\prime}$ \\
\hline Cox’s Bazar & 0.257 & 0.487 & 1.447 & -1.744 & 0.377 & -0.205 & -0.447 & 1.744 & -0.12 & 0.692 \\
Chittagong & 0.246 & 0.515 & 1.388 & -1.663 & 0.382 & -0.217 & -0.388 & 1.663 & -0.136 & 0.732 \\
Khulna & 0.239 & 0.519 & 1.519 & -1.886 & 0.386 & -0.219 & -0.519 & 1.886 & -0.147 & 0.738 \\
Barisal & 0.244 & 0.513 & 1.547 & -1.937 & 0.383 & -0.216 & -0.547 & 1.937 & -0.14 & 0.73 \\
Comilla & 0.234 & 0.536 & 1.45 & -1.772 & 0.388 & -0.227 & -0.45 & 1.772 & -0.153 & 0.763 \\
Dhaka & 0.232 & 0.553 & 1.495 & -1.853 & 0.389 & -0.234 & -0.495 & 1.853 & -0.156 & 0.787 \\
Rajshahi & 0.242 & 0.573 & 1.37 & -1.616 & 0.384 & -0.244 & -0.37 & 1.616 & -0.143 & 0.817 \\
Mymensingh & 0.249 & 0.526 & 1.521 & -1.898 & 0.381 & -0.222 & -0.521 & 1.898 & -0.133 & 0.748 \\
Sylhet & 0.254 & 0.516 & 1.514 & -1.871 & 0.379 & -0.218 & -0.514 & 1.871 & -0.125 & 0.734 \\
Rangpur & 0.236 & 0.543 & 1.466 & -1.798 & 0.387 & -0.23 & -0.466 & 1.798 & -0.15 & 0.773 \\
Average & 0.243 & 0.538 & 1.472 & -1.804 & 0.384 & -0.223 & -0.472 & 1.804 & -0.140 & 0.751 \\
\hline
\end{tabular}

over Bangladesh, even where the radiation data is missing or unavailable, is:

$$
\frac{G}{G_{o}}=0.240+0.534\left(\frac{n}{N}\right)
$$

which implies that about $24 \%$ of extraterrestrial radiation over Bangladesh filtrates the atmosphere into on a fully cloudy day $(n=0)$ and about $76 \%$ on a clear sky day respectively.

The maximum and minimum values of other regression coefficients and constants $c, d, c^{\prime}, d^{\prime}, e, f, e^{\prime}$ and $f^{\prime}$ are (1.547 and 1.37), (-1.616 and -1.937), (0.389 and 0.377), ( -0.205 and -0.244$),(-0.37$ and -0.547$)$, (1.983 and $1.616),(-0.12$ and -0.156$)$ and $(0.817$ and 0.692$)$ respectively.

Using the average values of the coefficients and constants in Equations (15-18), the linear equations recommended for the estimation of monthly averaged diffuse and direct solar radiation all over Bangladesh are:

$$
\begin{aligned}
\frac{D}{G_{o}} & =1.485-1.829\left(\frac{G}{G_{o}}\right) \\
\frac{D}{G_{o}} & =0.385-0.226\left(\frac{n}{N}\right)
\end{aligned}
$$




$$
\begin{aligned}
& \frac{I}{G}=-0.485+1.830\left(\frac{G}{G_{o}}\right) \\
& \frac{I}{G_{o}}=-0.145+0.760\left(\frac{n}{N}\right) .
\end{aligned}
$$

\subsection{Calculation of Monthly Averaged Daily Solar Radiation on Tilted Surface}

In the estimation of solar radiation on a tilted surface the angles of inclination have been chosen from $0^{\circ}$ to $90^{\circ}$ with an interval of $5^{\circ}$. Monthly averaged daily solar radiation on tilted surface for all the months of the year for different stations is shown in Figure 5.
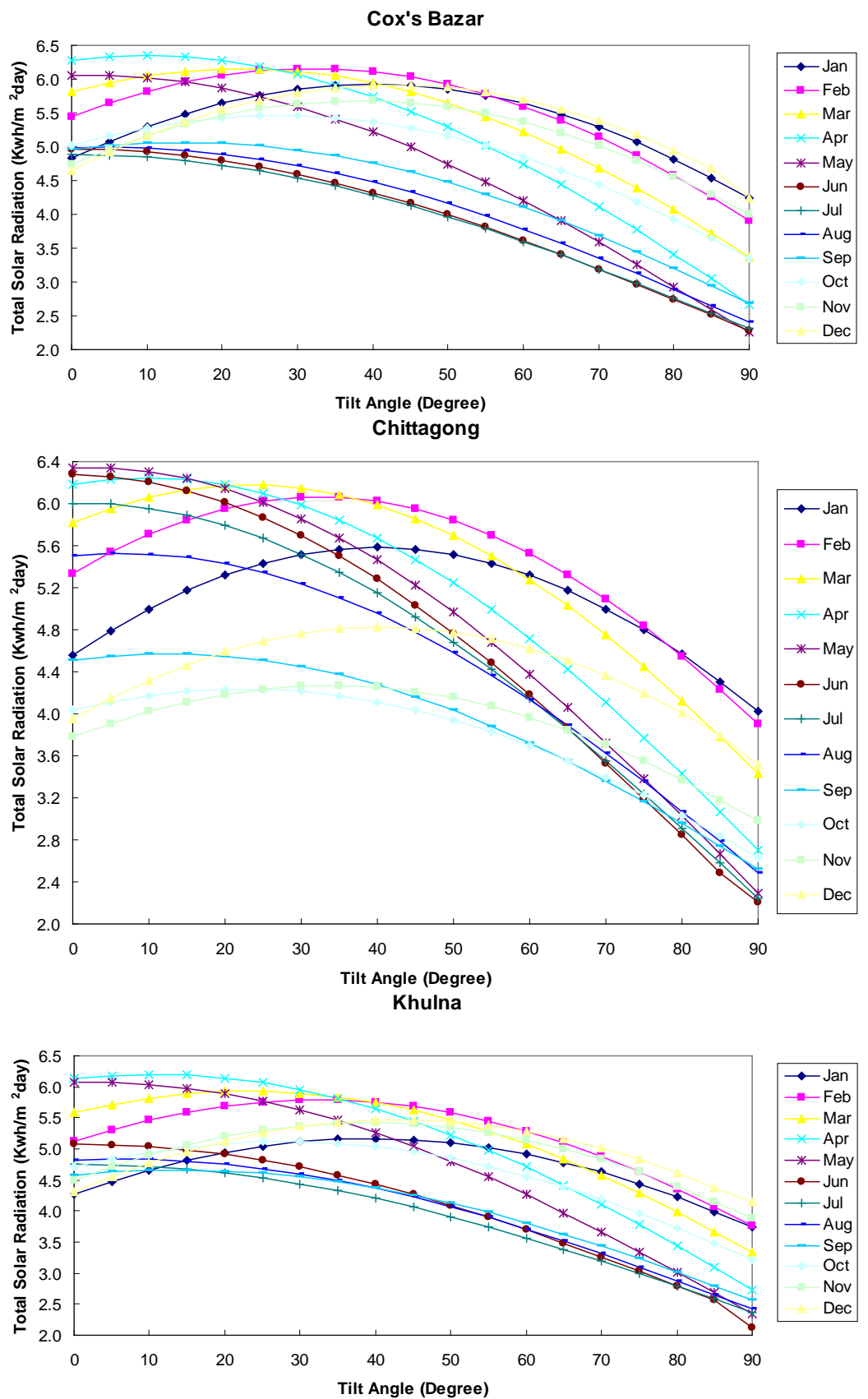
Barisal

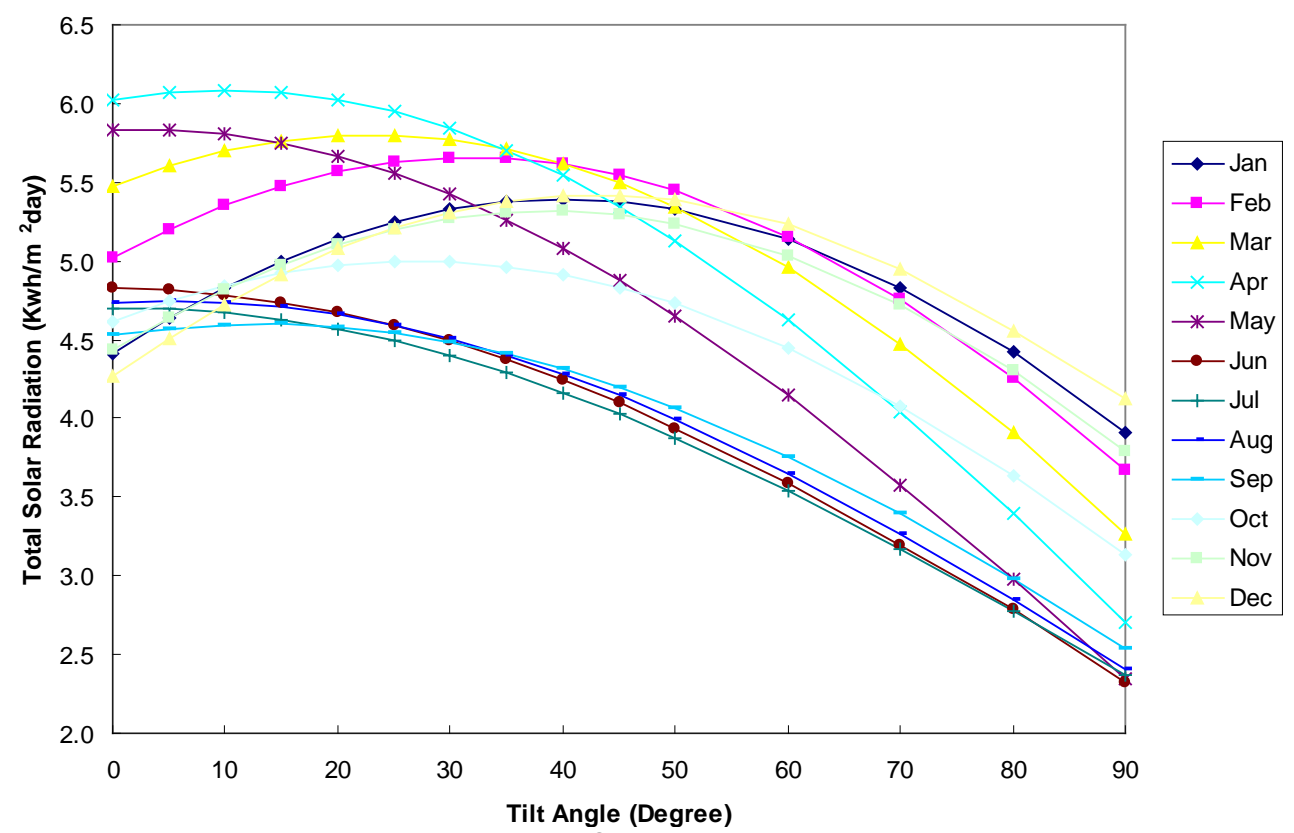

Comilla

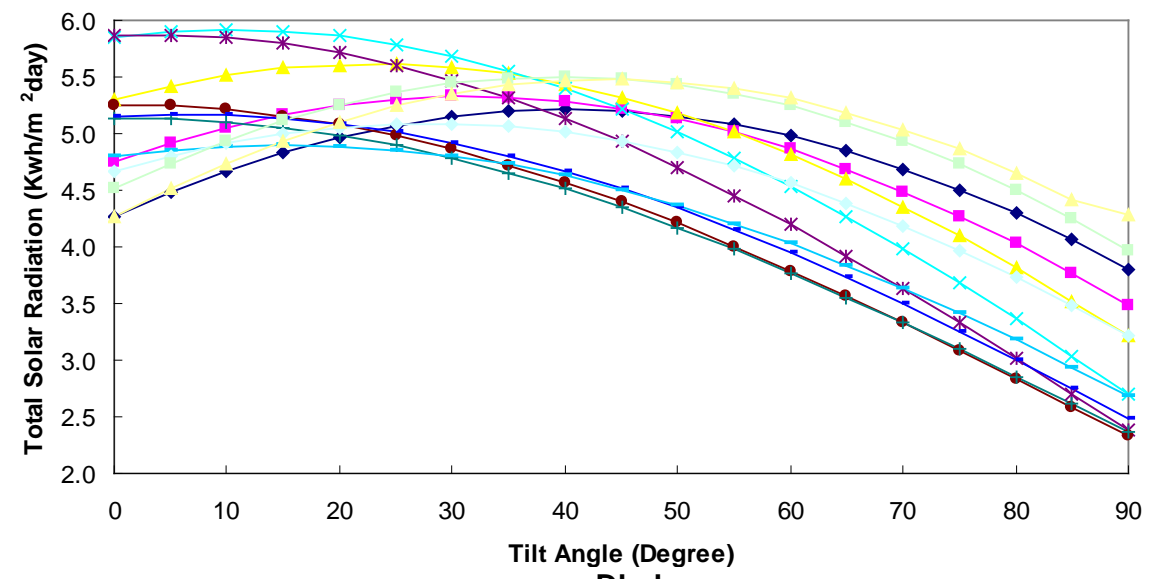

Dhaka

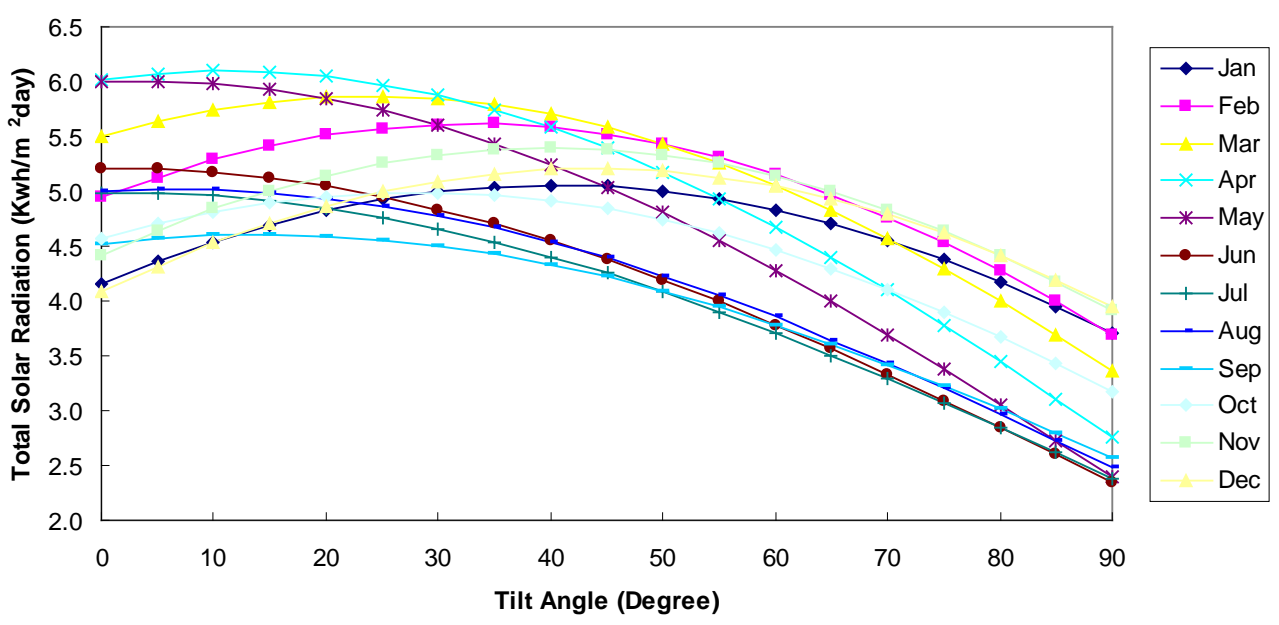



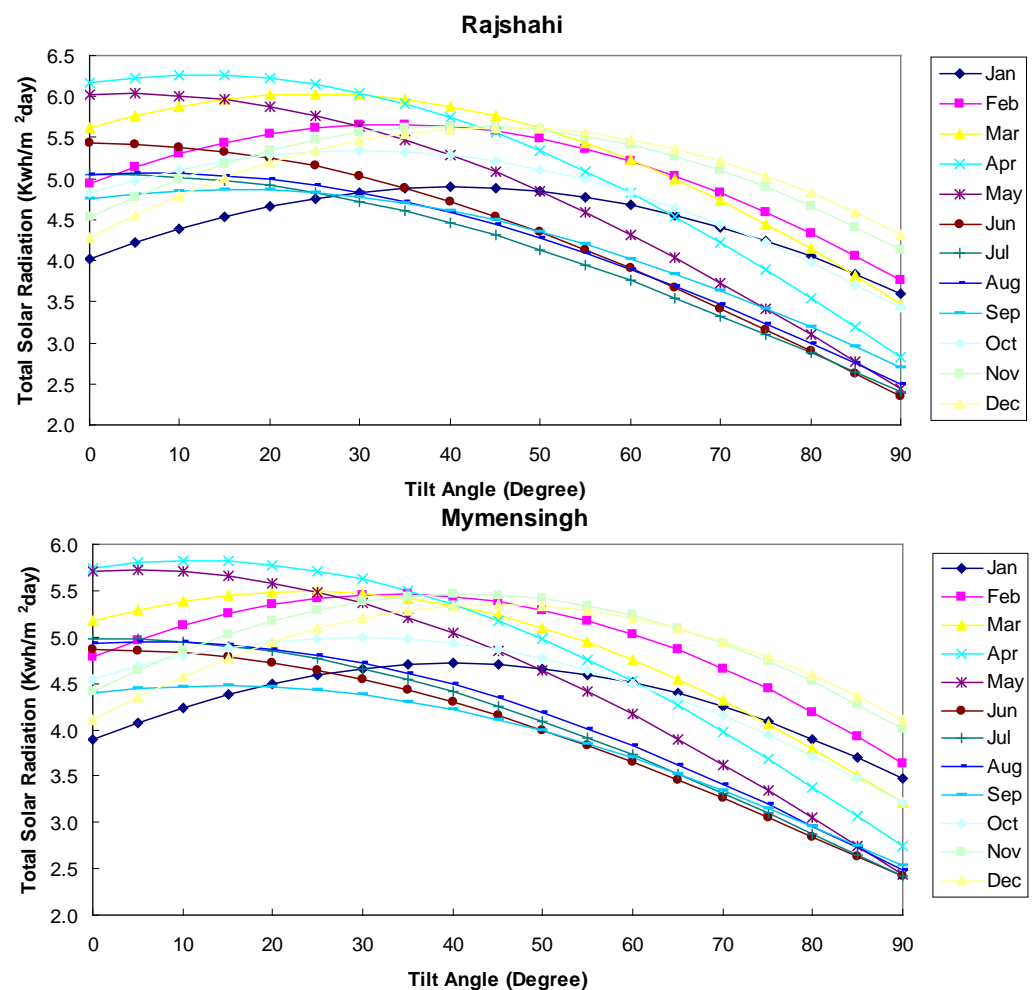

Sylhet

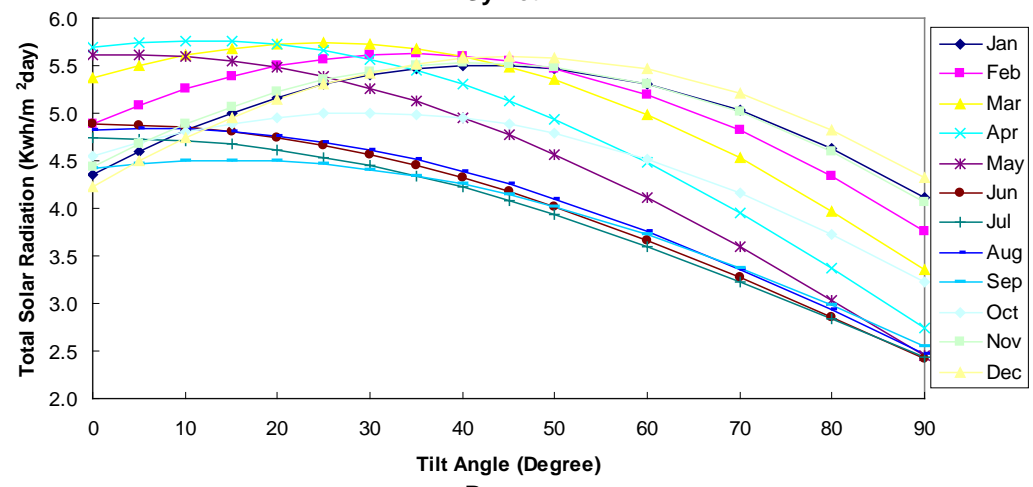

Rangpur

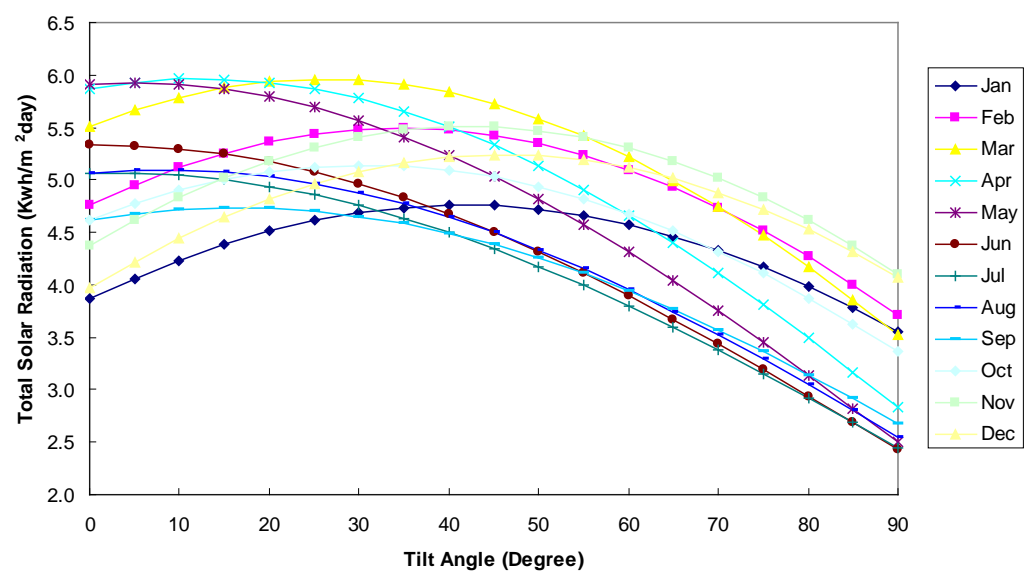

Figure 5. Illustrating the variation of monthly averaged daily total solar radiation for various inclination angles of different stations of Bangladesh. 
Divergent value of solar radiation is found due to various inclination angles for different month. An angle for which solar radiation becomes highest is called as optimal tilt angle which has been discussed hereafter. It is apparent that the highest value of annual total solar radiation is found for $20^{\circ}$ and $25^{\circ}$ inclination angles in different stations of Bangladesh and the lowest for $90^{\circ}$ inclination angle in all the stations of Bangladesh.

\subsection{Conversion Factor}

Conversion factor $R$ implies the ratio of radiation on tilted surface $G_{T}$ to radiation on horizontal surface. The value of $R$ depends upon the value of $G_{T}$ not on $G$. If the value of $G_{T}$ increases $R$ will also increase and if decreases $R$ will decrease because the value of $G$ is always fixed. The value of $G_{T}$ varies from month to month and angle to angle as well as location to location. The highest value of $R$ is found on optimal tilt surface for every distinct month. The value of $R$ is fluctuated highly with an increase of different angles when applied consecutively. A typical conversion factor for Sylhet station is presented below by Table 2 and Figure 6 and Figure 7.

\subsection{Optimal Tilt Angle}

Optimal tilt angle refers to such angle for which the value of solar radiation on that surface becomes highest. Figure 8 shows optimal tilt angle for every concerned station for every month, and Figure 9 shows optimal tilt angle for few stations of Bangladesh for the year round.

In January, the optimal tilt angle is $40^{\circ}$ for all the stations except Sylhet $\left(45^{\circ}\right)$. In February, the optimal tilt angle is $35^{\circ}$ for the stations Dhaka, Rajshahi, Sylhet, Rangpur, Mymensingh and $30^{\circ}$ for the stations Chittagong,

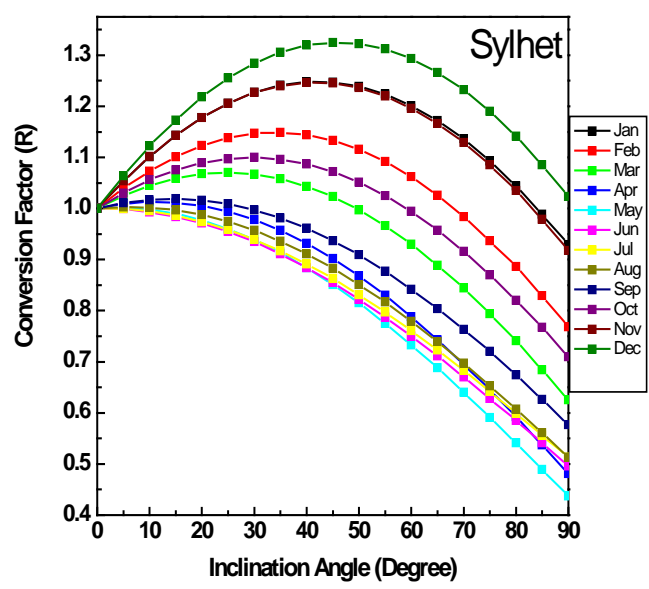

Figure 6. Conversion factor $R$, for various inclination angles for all month of the year.

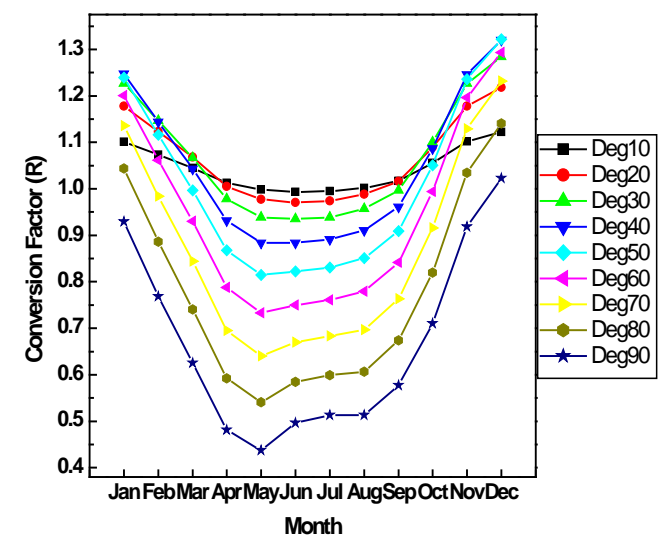

Figure 7. Conversion factor $R$, for various months of the year. 


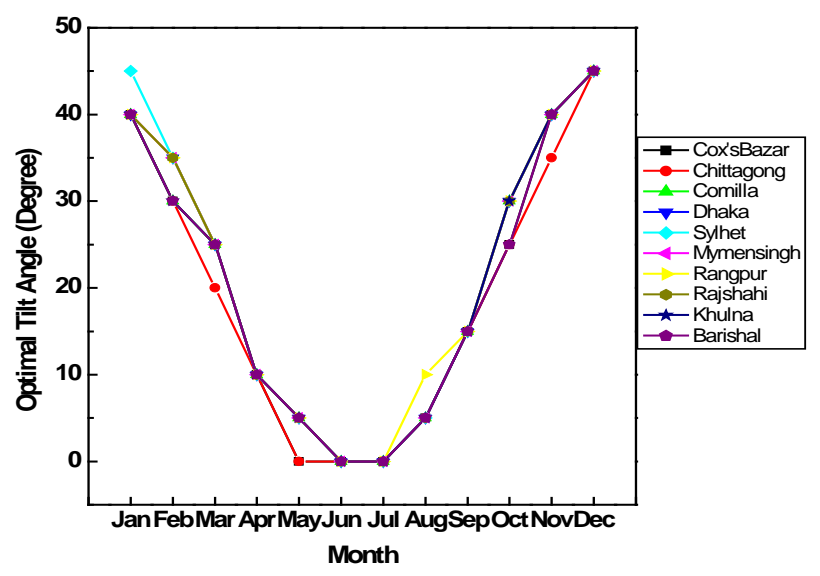

Figure 8. Monthly optimal tilt angle for different stations.

Table 2. Values of conversion factor $R$ for various inclination angles in Sylhet station.

\begin{tabular}{|c|c|c|c|c|c|c|c|c|c|c|c|c|}
\hline Month & & & & & & & & & & & & \\
\hline $\begin{array}{c}\text { Tilt angle } \\
\text { (degree) }\end{array}$ & Jan & Feb & Mar & Apr & May & Jun & Jul & Aug & Sep & Oct & Nov & Dec \\
\hline 0 & 1 & 1 & 1 & 1 & 1 & 1 & 1 & 1 & 1 & 1 & 1 & 1 \\
\hline 5 & 1.054 & 1.040 & 1.025 & 1.009 & 1.001 & 0.999 & 0.999 & 1.003 & 1.011 & 1.030 & 1.054 & 1.064 \\
\hline 10 & 1.101 & 1.073 & 1.045 & 1.013 & 0.998 & 0.993 & 0.995 & 1.002 & 1.017 & 1.056 & 1.102 & 1.122 \\
\hline 15 & 1.143 & 1.101 & 1.059 & 1.011 & 0.990 & 0.984 & 0.986 & 0.997 & 1.019 & 1.075 & 1.143 & 1.173 \\
\hline 20 & 1.178 & 1.123 & 1.068 & 1.005 & 0.977 & 0.971 & 0.974 & 0.988 & 1.016 & 1.089 & 1.178 & 1.218 \\
\hline 25 & 1.206 & 1.138 & 1.070 & 0.994 & 0.960 & 0.955 & 0.959 & 0.975 & 1.009 & 1.097 & 1.206 & 1.255 \\
\hline 30 & 1.227 & 1.147 & 1.067 & 0.978 & 0.939 & 0.935 & 0.939 & 0.957 & 0.997 & 1.100 & 1.227 & 1.284 \\
\hline 35 & 1.241 & 1.149 & 1.058 & 0.957 & 0.914 & 0.911 & 0.917 & 0.936 & 0.981 & 1.096 & 1.240 & 1.306 \\
\hline 40 & 1.248 & 1.144 & 1.043 & 0.932 & 0.884 & 0.884 & 0.891 & 0.911 & 0.961 & 1.087 & 1.246 & 1.320 \\
\hline 45 & 1.247 & 1.133 & 1.023 & 0.902 & 0.851 & 0.855 & 0.863 & 0.883 & 0.937 & 1.072 & 1.245 & 1.325 \\
\hline 50 & 1.239 & 1.116 & 0.997 & 0.868 & 0.815 & 0.822 & 0.831 & 0.851 & 0.909 & 1.051 & 1.236 & 1.322 \\
\hline 55 & 1.224 & 1.092 & 0.966 & 0.830 & 0.775 & 0.787 & 0.797 & 0.817 & 0.877 & 1.025 & 1.220 & 1.312 \\
\hline 60 & 1.201 & 1.062 & 0.930 & 0.788 & 0.733 & 0.750 & 0.761 & 0.779 & 0.842 & 0.994 & 1.196 & 1.293 \\
\hline 65 & 1.172 & 1.026 & 0.889 & 0.743 & 0.688 & 0.711 & 0.723 & 0.739 & 0.804 & 0.957 & 1.166 & 1.266 \\
\hline 70 & 1.136 & 0.984 & 0.844 & 0.695 & 0.640 & 0.670 & 0.683 & 0.697 & 0.763 & 0.916 & 1.129 & 1.232 \\
\hline 75 & 1.093 & 0.937 & 0.794 & 0.645 & 0.591 & 0.628 & 0.642 & 0.653 & 0.720 & 0.870 & 1.085 & 1.190 \\
\hline 80 & 1.044 & 0.886 & 0.741 & 0.592 & 0.541 & 0.585 & 0.599 & 0.607 & 0.674 & 0.820 & 1.035 & 1.141 \\
\hline 85 & 0.989 & 0.829 & 0.684 & 0.537 & 0.489 & 0.541 & 0.556 & 0.561 & 0.626 & 0.767 & 0.979 & 1.085 \\
\hline 90 & 0.929 & 0.768 & 0.625 & 0.481 & 0.437 & 0.496 & 0.513 & 0.513 & 0.577 & 0.710 & 0.918 & 1.023 \\
\hline
\end{tabular}

Khulna, Barisal, Comilla and Cox's Bazar. In March, the optimal tilt angle is $25^{\circ}$ excluding Chittagong (20 $)$. In April, the optimal tilt angle is $10^{\circ}$. In May, the optimal tilt angle is $5^{\circ}$ except two stations (Chittagong, Cox's Bazar) where their optimal tilt angle is $0^{\circ}$. In June \& July, the optimal tilt angle is $0^{\circ}$ for all the stations. In August, the optimal tilt angle is $5^{\circ}$ for all the stations except one station (Rangpur) where its optimal tilt angle is $10^{\circ}$. In September, the optimal tilt angle is $15^{\circ}$. In October, the optimal tilt angle is $30^{\circ}$ for all the stations except 3 stations (Chittagong, Barisal, Cox’s Bazar), where their optimal tilt angle is $25^{\circ}$. In November, the optimal tilt angle is $40^{\circ}$ for all the stations except Chittagong $\left(35^{\circ}\right.$ ). In December, the optimal tilt angle is $45^{\circ}$ for all the sta- 
tions.

The optimal tilt angle is mainly depends on Sun's declination and latitude. When the sun's declination increases from December solastic to June solastic, then the value of optimal tilt angle decreases. After June solastic the declination decreases and the value of optimal tilt angle increases. In December the optimal tilt angle is $45^{\circ}$ when the declination is $-21.16^{\circ}$, while the optimal tilt angle is $0^{\circ}$ for June \& July when the declination is from $+23.17^{\circ}$ to $+21.37^{\circ}$. For the same month, the optimal tilt angle varies with latitude. The value of optimal tilt angle also depends on weather condition. That is why, the value of ground reflected radiation rate is higher in fine days than cloudy days. So the value of optimal tilt angle is higher in fine days than cloudy days.

\subsection{Monthly Averaged Daily Beam, Diffuse, Ground Reflected and Total Solar Radiation on Tilted Surface in Dhaka}

Total solar radiation on tilted surface consists of ground reflected, diffuse and beam radiation. The value of ground reflected radiation increases with the increase of the inclination angle. For this reason the lowest value of ground reflected radiation is found for $0^{\circ}$ angle and the highest for $90^{\circ}$ angle for the whole year and all stations as aforesaid in Bangladesh. The value of diffuse radiation always decreases with the increase of inclination angle owing to the value of scattered and reflected radiation on tilted surface decreases. That is why; the highest value of diffuse radiation is seen for $0^{\circ}$ angle and the lowest for $90^{\circ}$ inclination angle, for all month in the year and all stations in Bangladesh. The value of beam radiation relies upon various inclination angles and the highest value of beam radiation is found on the optimal tilt surface. Figure 10 shows the variation of different radiation for various inclination angles in Dhaka station.

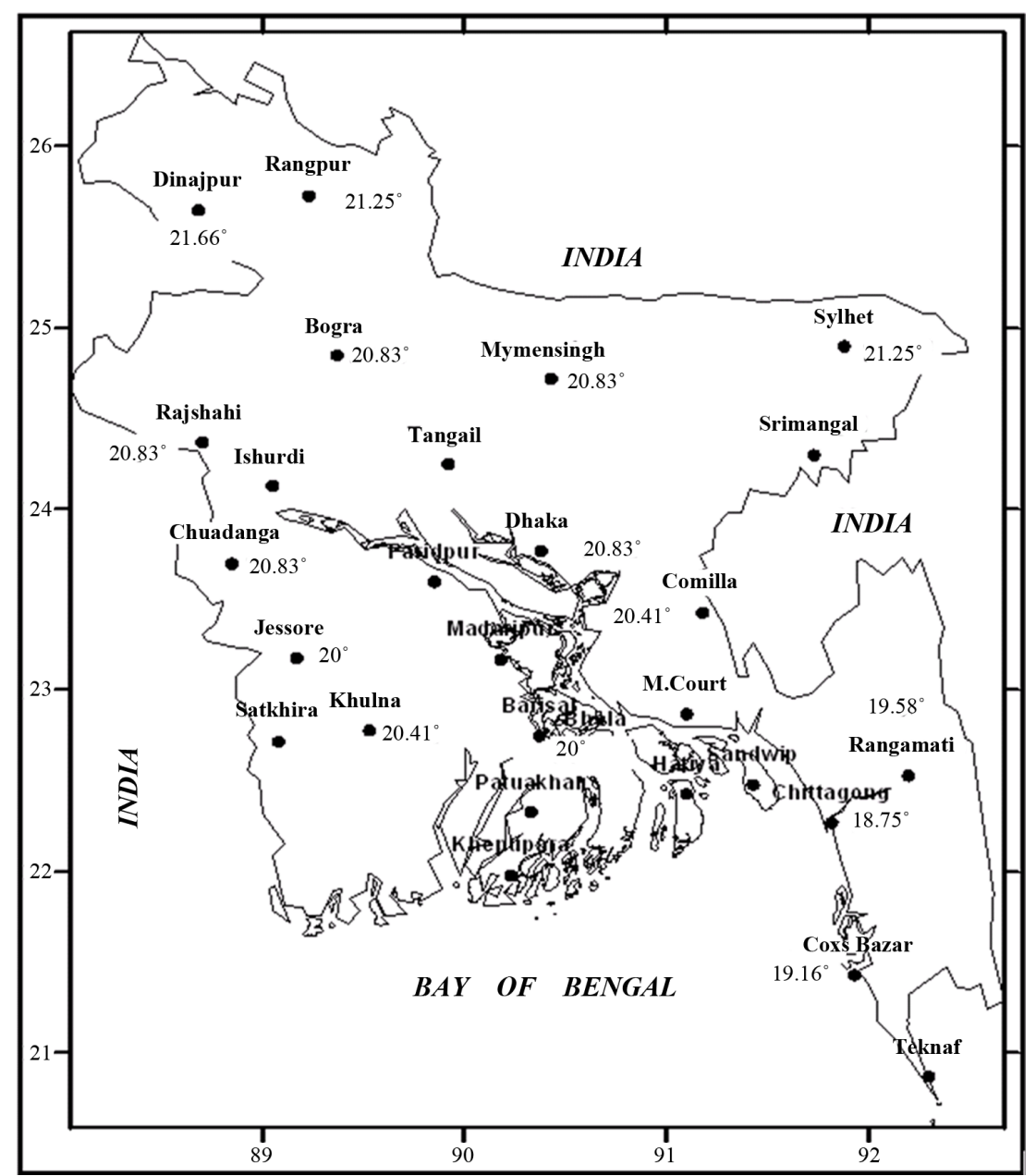

Figure 9. Yearly optimal tilt angle for different stations. 

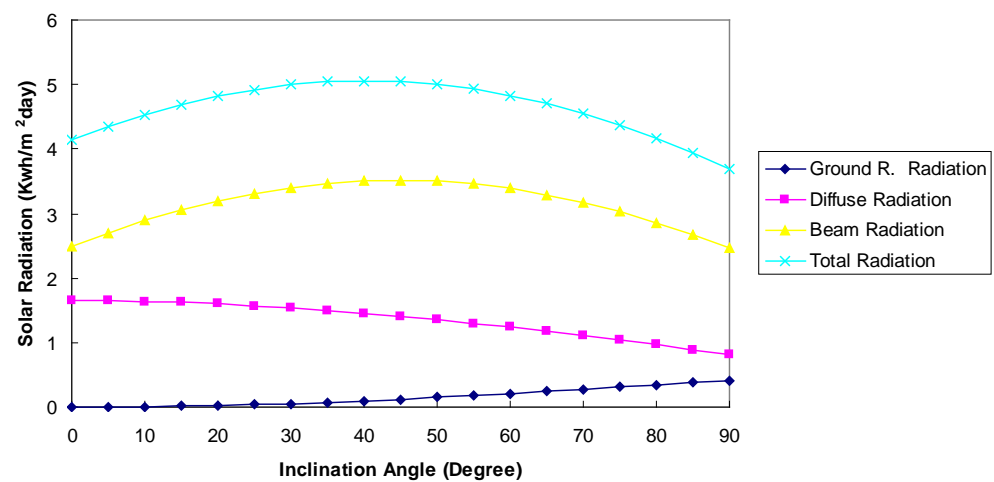

(a)

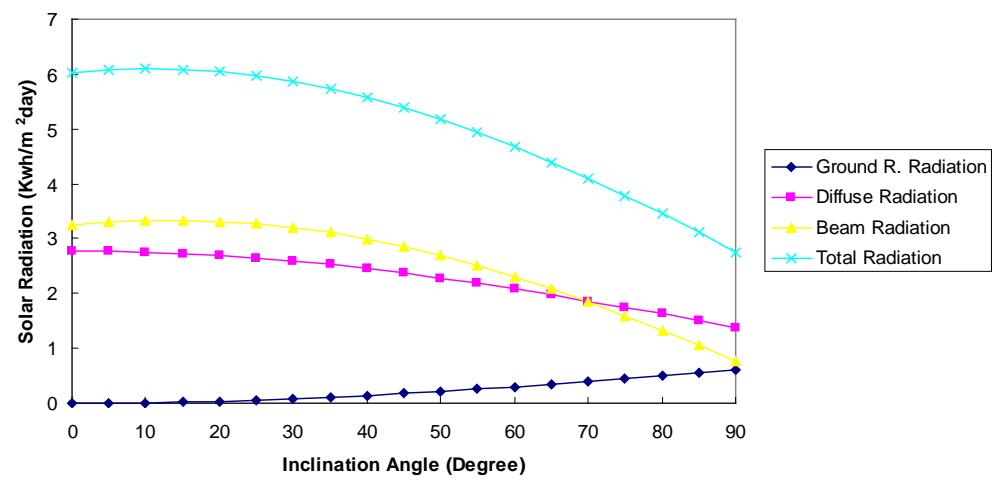

(b)

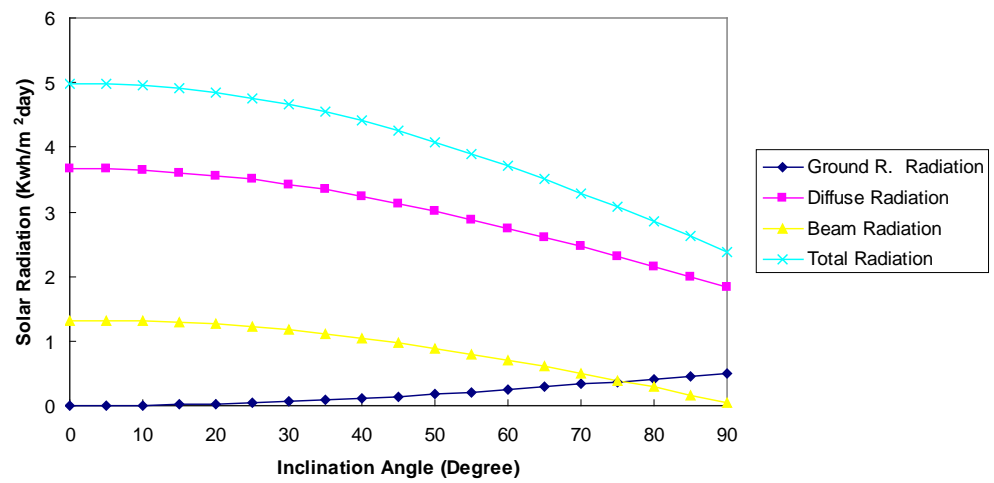

(c)

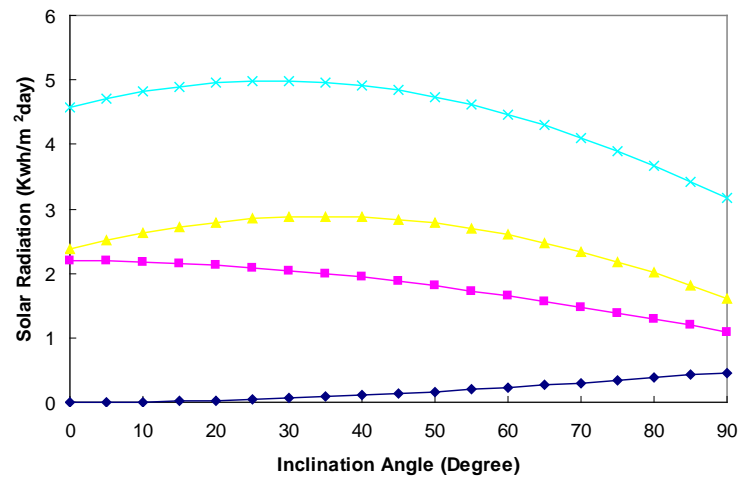

- — Ground R. Radiation

- Diffuse Radiation

Beam Radiation

-Total Radiation

(d)

Figure 10. Variation of ground reflected, diffuse, beam and total solar radiation for various inclination angles in Dhaka for month January (a), April (b), July (c) and October (d). 


\subsection{Comparison of Solar Radiation on Horizontal Surface and Tilted Surface at Dhaka Station}

In January, we have found the value of solar radiation is $5.058 \mathrm{Kwh} / \mathrm{m}^{2}$ day for optimal tilt angle $40^{\circ}$. On the other hand, the value of solar radiation is $4.149 \mathrm{Kwh} / \mathrm{m}^{2}$ day on horizontal surface. Therefore, we get $22 \%$ gain on optimal tilt surface with respect to horizontal surface. For the other months solar radiation on optimal tilt surface and horizontal surface, and gain also are shown in Table 3 . The average value of solar radiation is 5.337 $\mathrm{Kwh} / \mathrm{m}^{2}$ day for the optimal tilt angle $20.833^{\circ}$ whereas the average value of solar radiation is $4.952 \mathrm{Kwh} / \mathrm{m}^{2}$ day on the horizontal surface. So, the average gain is $8.71 \%$ on optimal tilt angle with respect to horizontal surface for the whole year.

In January, we have found the value of solar radiation is $4.831 \mathrm{Kwh} / \mathrm{m}^{2}$ day on fixed $20.83^{\circ}$ tilt surface. On the other hand, the value of solar radiation is $4.149 \mathrm{Kwh} / \mathrm{m}^{2}$ day on horizontal surface. Therefore, we get $16.43 \%$ gain on fixed tilt surface with respect to horizontal surface. For the other months solar radiation on fixed tilt surface and horizontal surface, and gain also are shown in Table 4. The average value of solar radiation is 5.213 $\mathrm{Kwh} / \mathrm{m}^{2}$ day on fixed $20.83^{\circ}$ tilt surface whereas the average value of solar radiation is $4.952 \mathrm{Kwh} / \mathrm{m}^{2}$ day on the horizontal surface. So, the average gain is $5.977 \%$ on fixed tilt surface with respect to horizontal surface for the whole year. Variable optimal tilt surface gives another interesting result in terms of solar radiation. Solar radiation on variable optimal tilt surface is equal or higher than that of solar radiation on horizontal surface or solar radiation on fixed $20.83^{\circ}$ tilt surface. Figure 11 shows the maximum value of solar radiation on variable optimal tilt surface.

Table 3. Extra Solar radiation gain on variable optimal tilt surface from horizontal surface of Dhaka station.

\begin{tabular}{cccccc}
\hline Month & $\begin{array}{c}\text { Optimal tilt angle } \\
\text { (degree) }\end{array}$ & $\begin{array}{c}\text { Solar radiation on optimal } \\
\text { tilt surface }\left(\mathrm{Kwh} / \mathrm{m}^{2} \text { day }\right)\end{array}$ & $\begin{array}{c}\text { Solar radiation on horizontal } \\
\text { surface }\left(\mathrm{Kwh} / \mathrm{m}^{2} \text { day) }\right.\end{array}$ & $\begin{array}{c}\text { Difference } \\
\left(\mathrm{Kwh} / \mathrm{m}^{2} \text { day) }\right.\end{array}$ & Efficiency (\%) \\
\hline Jan & 40 & 5.058 & 4.149 & 0.909 & 22 \\
Feb & 35 & 5.612 & 4.942 & 0.67 & 14 \\
Mar & 25 & 5.864 & 5.502 & 0.362 & 6.58 \\
Apr & 10 & 6.095 & 6.02 & 0.075 & 1.246 \\
May & 5 & 6.007 & 6.002 & 0.005 & 0.08 \\
Jun & 0 & 5.213 & 5.213 & 0 & 0 \\
Jul & 0 & 4.99 & 4.99 & 0 & 0 \\
Aug & 5 & 5.019 & 5.003 & 0.016 & 0.31 \\
Sep & 15 & 4.602 & 4.521 & 0.081 & 1.8 \\
Oct & 30 & 4.984 & 4.576 & 0.408 & 8.92 \\
Nov & 40 & 5.394 & 4.422 & 0.972 & 22 \\
Dec & 45 & 5.208 & 4.082 & 1.126 & 27.58 \\
Average & 20.833 & 5.337 & 4.952 & 0.385 & 8.710 \\
\hline
\end{tabular}

Table 4. Extra solar radiation gain on fixed $20.83^{\circ}$ tilt surface from horizontal surface of Dhaka station.

\begin{tabular}{|c|c|c|c|}
\hline Month & $\begin{array}{l}\text { Solar radiation on horizontal } \\
\text { surface (Kwh/m² day) }\end{array}$ & $\begin{array}{l}\text { Solar radiation on fixed } 20.83^{\circ} \text { tilt } \\
\text { surface (Kwh/m } / \mathrm{m}^{2} \text { day) }\end{array}$ & Efficiency (\%) \\
\hline Jan & 4.149 & 4.831 & 16.430 \\
\hline Feb & 4.942 & 5.520 & 11.690 \\
\hline Mar & 5.502 & 5.865 & 6.590 \\
\hline Apr & 6.020 & 6.055 & 0.581 \\
\hline May & 6.002 & 5.857 & -2.415 \\
\hline Jun & 5.213 & 5.053 & -3.069 \\
\hline Jul & 4.990 & 4.860 & -2.605 \\
\hline Aug & 5.003 & 4.949 & -1.079 \\
\hline Sep & 4.521 & 4.598 & 1.703 \\
\hline Oct & 4.576 & 4.960 & 8.391 \\
\hline Nov & 4.422 & 5.132 & 16.056 \\
\hline Dec & 4.082 & 4.876 & 19.451 \\
\hline Average & 4.952 & 5.213 & 5.977 \\
\hline
\end{tabular}




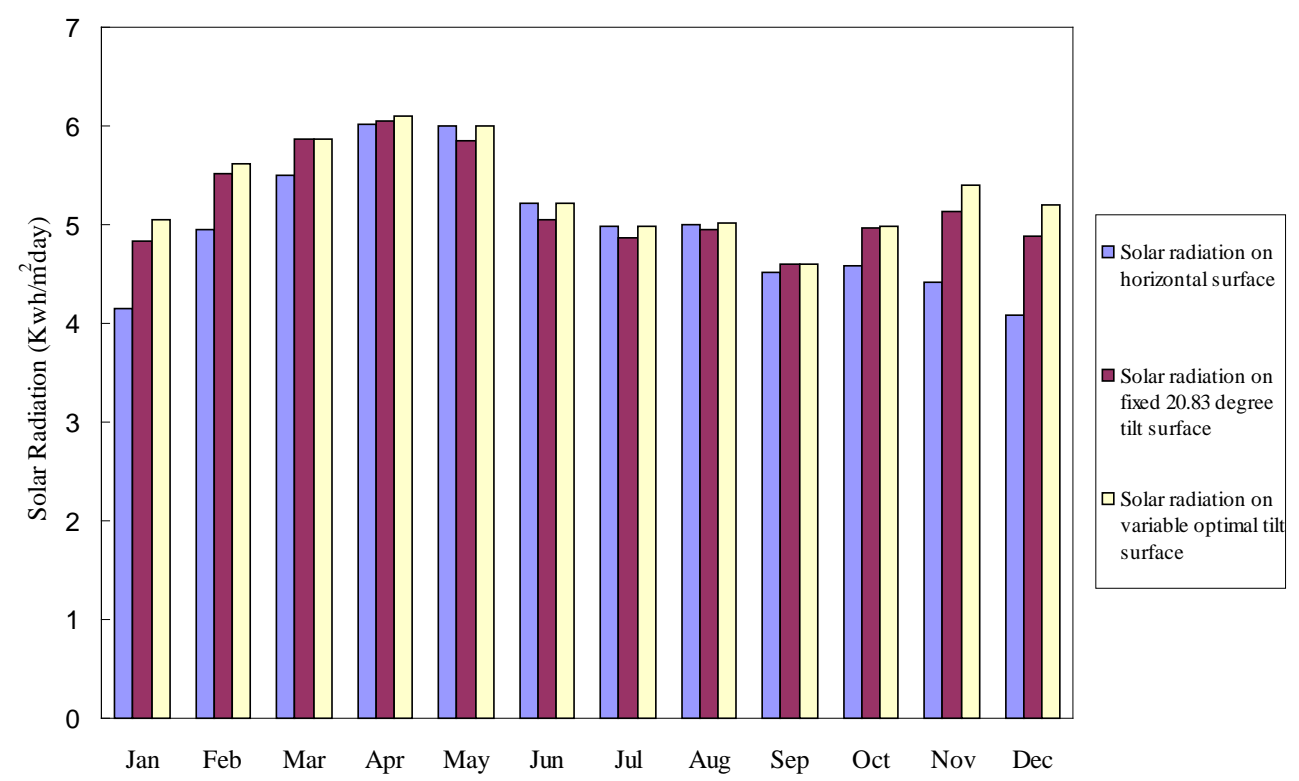

Figure 11. Comparison in terms of irradiance per day among horizontal surface, fixed tilt surface, variable optimal tilt surface.

\section{Conclusion}

Energy is very important part for every country and every person. But energy crisis is vital problem in the world at present. Our Bangladesh also faces mostly energy problem now. At this energy situation solar energy can be mitigated our energy problem. The research work reported in this paper will help regard state of knowledge relating to solar radiation on horizontal and tilted surface and estimate the solar energy potential for practical and efficient utilization in Bangladesh. That is why it will encourage the interested personnel dealing with promotion of solar energy throughout the country to install economically viable solar device by taking into account abovementioned observation under which increased solar energy can be found. Ultimately it may mitigate energy crisis and thereby reduce sufferings of the general people as well as lessen investment crisis in Bangladesh.

\section{Acknowledgements}

Authors thank Dr. Md. Nurul Islam, Dept. of Physics, University of Chittagong for helpful discussions and Mr. Md. Abdul Mannan, Meteorologist, Bangladesh Meteorological Dept. for the cooperation in collecting data.

\section{References}

[1] International Energy Agency (IEA) Statics Division (2007) Energy Balances of OECD Countries (2008 Edition) and Energy Balances of Non-OECD Countries (2007 Edition). IEA, Paris.

[2] (2003) Statistical Pocketbook of Bangladesh.

[3] Islam, M.N. (2000) Energy Security Issues of Bangladesh, Engineering News. 1st Issue, Engineers Institution Bangladesh.

[4] Codato, G., Oliveira, A.P., Soares, J., Escobedo, J.F., Gomes, E.N. and Pai, A.D. (2008) Global and Diffuse Solar Irradiances in Urban and Rural Areas in Southeast Brazil. Theorical Applied Climatology, 93, 57-73. http://dx.doi.org/10.1007/s00704-007-0326-0

[5] Escobedo, J.F., Gomes, E.N., Oliveira, A.P. and Soares, J. (2009) Modeling Hourly and Daily Fractions of UV, PAT and NIR to Global Solar Radiation under Various Sky Conditions at Botucatu, Brazil. Applied Energy, 86, $299-309$. http://dx.doi.org/10.1016/j.apenergy.2008.04.013

[6] World Meteorological Organization (1985) Guide to Meteorological Instruments and Observing Practices. WMO No. 8, TP3, Geneva.

[7] Liu, B.Y.H. and Jordan, R.C. (1962) Daily Insolation on Surfaces Tilted towards the Equator. ASHRAE Transactions, 67, 526-541. 
[8] Klein, S.A. (1977) Calculation of Monthly Average Insolations on Tilted Surfaces. Solar Energy, 19, 325-329. http://dx.doi.org/10.1016/0038-092X(77)90001-9

[9] Nahar, S., Golam Sarwar, A.T.M. and Chowdhury, S.A. (2009) A Theoretical Analysis of Optimizing Solar Irradiance: Bangladesh Perspective. 1st International Conference on the Developments in Renewable Energy Technology, Dhaka, 17-19 December 2009, 161-164. http://dx.doi.org/10.1109/icdret.2009.5454191 